\title{
Comparing techniques for pterygium surgery
}

\author{
Atilla Alpay \\ Suat Hayri Uğurbaş \\ Berktuğ Erdoğan \\ Department of Ophthalmology, \\ Faculty of Medicine, Zonguldak \\ Karaelmas University, Zonguldak, \\ Turkey
}

\begin{abstract}
Purpose: To compare various techniques of pterygium surgery including bare sclera, intraoperative mitomycin $\mathrm{C}$ application, conjunctival flap reconstruction, and conjunctival autografting technique.

Methods: This study is designed to compare 4 currently used techniques in order to determine the complication and recurrence rates after pterygium exision. Included in the study were 77 eyes from 60 patients. Bare sclera technique was used to treat 21 primary pterygia;mitomycin $\mathrm{C}$ was used to treat 20 (16 primary, 4 recurrent) pterygia;18 (17 primary, 1 recurrent) pterygia were treated by conjuntival flap reconstruction;and 18 ( 9 primary, 9 recurrent) pterygia were treated by conjunctival autografting technique. All patients who underwent surgery were followed up for between 6 months and 2 years.

Results: Eight recurrences (38.09\%) were observed in the bare sclera group whereas there were $5(25 \%)$ recurrences in the mitomycin $\mathrm{C}$ group. In the conjunctival flap reconstruction group, $6(33.33 \%)$ recurrences were detected. In the conjunctival autografting group, 3 recurrences were observed. There were no major complications threatening visual ability in the surgical patients.

Conclusion: A comparison of the groups demonstrated that the recurrence rate was highest in the bare sclera group, and lowest in conjunctival autografting and mitomycin $\mathrm{C}$ treatment groups respectively. Although the conjunctival autografting technique is a more difficult and time consuming technique than the others, cosmetic and surgical results were found to be superior. We advise conjunctival autografting for the treatment of pterygium in view of the high recurrence rates of other techniques, and the possible complications of mitomycin $\mathrm{C}$ treatment for benign disease.

Keywords: pterygium, comparing, techniques, mitomycin C
\end{abstract}

\section{Introduction}

Pterygium is a growth of fibrovascular tissue on the cornea, which appears to be continuous with the conjunctiva. ${ }^{1}$ Prevalence rates range from $0.7 \%$ to $31 \%$ in various populations around the world, and the condition is more common in warm, dry climates. ${ }^{2}$ Treatment of pterygium is surgical. In general, conservative therapy for pterygium is warranted unless one of the following circumstances arises: loss of visual acuity either because of induced astigmatism or encroachment onto the visual axis, marked cosmetic deformity, marked discomfort and irritation unrelieved by medical management, limitation of ocular motility secondary to restriction, or documented progressive growth toward the visual axis so that ultimate loss of vision can reasonably be assumed. In such circumstances, surgical intervention is required. Because recurrences after pterygia excision are frequent and aggressive, firm indications for surgical removal should exist before primary excision. The fact that numerous different techniques exist for the surgical treatment of pterygium underscores the point that no single approach is universally successful. ${ }^{3}$ The purpose of this study is to compare the four currently used techniques.

\section{Materials and methods}

Of the 60 patients who were underwent surgery for pterygium at the Ophthalmology Clinic, Zonguldak Karaelmas University Faculty of Medicine, between February 
2001 and October 2004. Seventy-seven eyes were examined retrospectively. Patients were categorized in four groups according to the type of operation: 42 male and 35 female patients were included in the study. The patient's ages ranged from 22 to 72 years and their average age was $46.4 \pm 2.7$ years.

Surgical excision with bare sclera technique was performed on 21 eyes (27.27\%). Intraoperative mitomycin C was applied to 20 eyes (25.97\%) after surgical excision. Bare sclera was repaired using the conjunctival flap technique, after surgical excision in 18 eyes (23.37\%). After surgical excision, the conjunctival autografting technique was used to treat 18 eyes $(23.37 \%)$; 63 primary and 14 recurrent pterygia were detected (Table 1).

Before surgery, the best-corrected Snellen visual acuity, intraocular pressure (by Goldmann applanation tonometry), and details of slit-lamp and fundus examinations were recorded. The mean size of pterygia was $3 \mathrm{~mm}$ (range, 2-4 mm). There were no differences in mean size between the four groups. Surgical procedures were performed under local anesthesia using an operation microscope by a single surgeon. A speculum was applied to the eye after local anesthetic agent application. The area surrounding the conjunctival part of the pterygium was marked with a marker pen, and $0.5 \mathrm{~mL}$ of local anesthetic lidocaine HCL $20 \mathrm{mg} / \mathrm{mL}$ + epinephrine $0.0125 \mathrm{mg} / \mathrm{mL}$ was injected under the pterygium body with a 25 -gauge neddle. A crescent blade was used to excise the corneal part of the pterygium. The excision was started from the $0.5 \mathrm{~cm}$ transparent cornea through the limbus constituting a regular plane. As the limbus passed, pterygium was extracted with the tenon under the body using a pair of wescot scissors with attention to the marked area.

When the bare sclera technique was used after pterygium excision, the eyes were closed with a rondel after the application of antibiotic ointment.

Pterygium excision was performed on the intraoperative mitomycin $\mathrm{C}$ group in the way described above. After bare sclera excision, a cellulose sponge $3 \mathrm{~mm} \times 4 \mathrm{~mm}$ containing $0.2 \mathrm{mg} / \mathrm{mL}$ mitomycin $\mathrm{C}$ was applied directly to the scleral bed, $2 \mathrm{~mm}$ from the limbus for 2 minutes. We took great care not bring mitomycin $\mathrm{C}$ into contact with the cornea while the sponge was in the cap. The sponge was taken out of the cap after 2 minutes. The area was irrigated with $200 \mathrm{~mL}$ of normal saline solution to clear mitomycin $\mathrm{C}$ residues. The conjunctiva was closed together with a size $8 / 0$ vicryl suture, leaving a 4-mm bare sclera. Afterwards the eye of the patient was closed with a rondell after the application of antibiotic ointment.

Complete resection of the pterygium body and Tenon's capsule was performed using the conjunctival flap technique. The conjuctival flap was subsequently made from the superior conjunctiva near the limbus. The flap was then thinly dissected, avoiding the Tenon's capsule, and carefully transposed to the pterygium excision site. The flap was secured to the adjacent conjunctiva with a running suture of $8-0$ vicryl. The cut edges of the conjunctiva on the donor site were pulled to cover the bare sclera and anchored in the limbus with 8-0 vicryl.

In conjunctival autografting, the pterygium was extracted as described above, and the dimensions of bare sclera was measured. Superior temporal conjunctiva of the same eye, approximately $1 \mathrm{~mm}$ greater than bare sclera size, was

Table I Demographic characteristic of patients

\begin{tabular}{|c|c|c|c|c|c|c|c|c|c|c|c|}
\hline \multicolumn{2}{|c|}{ Treatment procedure } & \multicolumn{2}{|c|}{ Bare sclera } & \multicolumn{2}{|l|}{ Mitomycin } & \multicolumn{2}{|c|}{ Conjunctival flap } & \multicolumn{2}{|l|}{ Autograft } & \multicolumn{2}{|l|}{ Total } \\
\hline Age (mean) & Primer & $\begin{array}{l}23-68 \\
(46.42)\end{array}$ & Total & $\begin{array}{l}22-68 \\
(46.05)\end{array}$ & Total & $\begin{array}{l}27-72 \\
(51.58)\end{array}$ & Total & $\begin{array}{l}23-65 \\
(46.22)\end{array}$ & Total & $\begin{array}{l}22-72 \\
(48.33)\end{array}$ & Total \\
\hline & Recurrent & - & $\begin{array}{l}23-68 \\
(46.42)\end{array}$ & $\begin{array}{l}38-49 \\
(45.50)\end{array}$ & $\begin{array}{l}22-68 \\
(47.95)\end{array}$ & $\begin{array}{l}50 \\
(50.00)\end{array}$ & $\begin{array}{l}27-72 \\
(51.50)\end{array}$ & $\begin{array}{l}39-66 \\
(49.55)\end{array}$ & $\begin{array}{l}23-66 \\
(47.88)\end{array}$ & $\begin{array}{l}38-66 \\
(48.42)\end{array}$ & $\begin{array}{l}22-77 \\
(48.35)\end{array}$ \\
\hline Male & & 12 & & 12 & & 6 & & 12 & & 42 & \\
\hline Female & & 9 & & 8 & & 12 & & 6 & & 35 & \\
\hline Primer & Eye & 21 & & 16 & & 17 & & 9 & & 63 & \\
\hline Pterygia & Recurrence & 8 (38.09\%) & & $2(12.50 \%)$ & & 5 (29.4I\%) & & $5(29.41 \%)$ & & $15(23.80 \%)$ & \\
\hline Recurren & Eye & 0 & & 4 & & I & & 9 & & 14 & \\
\hline Pterygia & Recurrence & 0 & & $3(75 \%)$ & & I (100\%) & & $3(33.33 \%)$ & & $7(50 \%)$ & \\
\hline $\begin{array}{l}\text { Total recurrence } \\
\text { rate }\end{array}$ & & $8(38.09 \%)$ & & $5(25 \%)$ & & $6(33.33 \%)$ & & $3(16.6 \%)$ & & $22(28.57 \%)$ & \\
\hline $\begin{array}{l}\text { Recurrence } \\
\text { time (month) }\end{array}$ & & 4 & & 4 & & 3 & & 4 & & Mean: 3.75 & \\
\hline
\end{tabular}


measured and marked (Figure 1). The area under the marked space was inflated with lidocaine. The aim of this procedure was to ease the dissection of the conjunctiva from the tenon during autografting, and to obtain the thinnest possible conjunctiva. Afterwards, it was dissected as thinly as possible from the underlying adhesions. During the incising process we paid close attention to leaving the marked area within the autograft. In due course the autograft was freed by cutting the limbal edge of the conjunctiva (Figure 2). The autograft was flattened in place, and transferred to the receiver area by handling from the two limbal edges (Figure 3). The limbal side of the autograft was placed on the limbal area in the receiver area. As the autograft regularly flattened, it was sutured to the adjacent conjunctiva with continuous sutures and fixed to sclera at the limbus level (Figure 4). The autograft was sutured around the adjacent conjunctiva, and the eye closed with a rondell after application of antibiotic ointment application.

All cases were outpatients. Steroid and antibiotic drops were prescribed $4 \times$ per day to all patients after surgery. Patients were examined from the first postoperative day, then 1 week, 15 days and 1 month after surgery. Follow-up examinations were performed at 3-month intervals subsequently. Follow-up periods were between 6 months and 24 months. The criterion for recurrence was determined to be the invasion of cornea more than $1 \mathrm{~mm}$ in diameter beginning from the limbus by fibrovascular tissue derived from the operation site. ${ }^{4-6}$

The data obtained were evaluated by SPSS for Windows 11.0 programme (SPSS Inc., Chicago, IL, USA). Mean values were shown as arithmetical mean value \pm standard error. Q square test, Fisher's exact q square test,

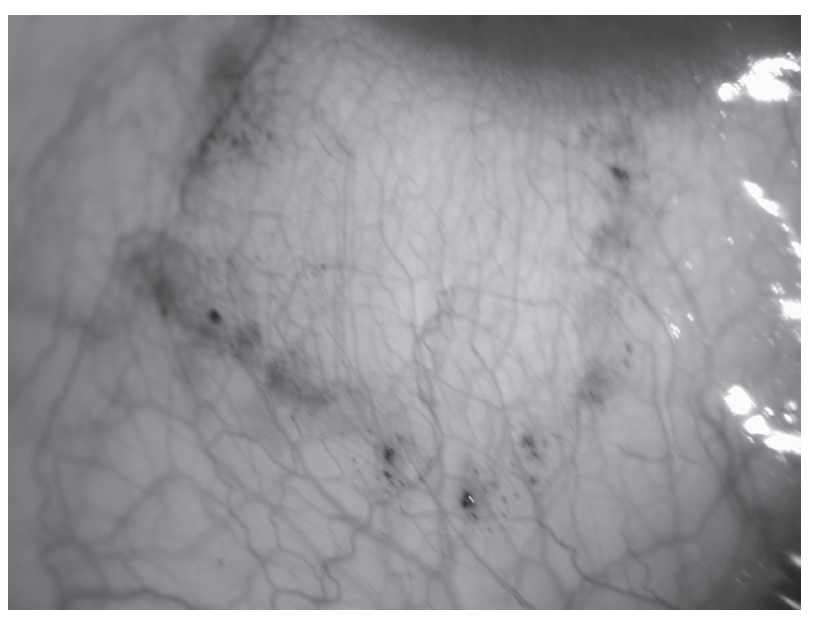

Figure I Marking of donor conjunctival site. and Kruskal-Wallis analysis of variance were used to compare groups. Results of the analysis were evaluated at $95 \%$ confidence interval.

\section{Results}

In our study we excised the pterygia in 77 eyes of 60 patients. Recurrence was observed in 22 cases, with an overall rate of $28 \%$. The pterygium was primary in all cases treated by the bare sclera method. A case of postoperative bacterial conjunctivitis was managed successfully in one week by administering antibiotic drops frequently and adding an antibiotic ointment twice a day to the treatment. Of 21 cases treated with bare sclera technique, 8 (38.09\%) experienced recurrence. Two of these patients were treated by mitomycin $\mathrm{C}$ and the other two by autografting technique. Because one of the mitomycin $\mathrm{C}$ patients suffered a further recurrence, autografting was the procedure of choice for a final operation. Mitomycin C was used on 20 patients, 16 of whom were primary and the rest were recurrent;five cases (25\%) experienced recurrence, two (12\%) of which were primary and the other three $(75 \%)$ were recurrent. Recurrent pterygia were treated by conjunctival autografting in two patients and with the conjunctival flap technique in one case. Conjunctival flap was performed in 18 cases, 17 of which were primary pterygia. The most common and persistent complaint was hyperemia at the operation site, which decreased and was resolved over a 2-month period. Recurrences were diagnosed in six (33.3\%) patients within three months. Five of these patients were primary and one was recurrent pterygium. Conjunctival autografting was practised on nine primary and nine recurrent pterygia. Postoperative autograft edema was observed in three patients

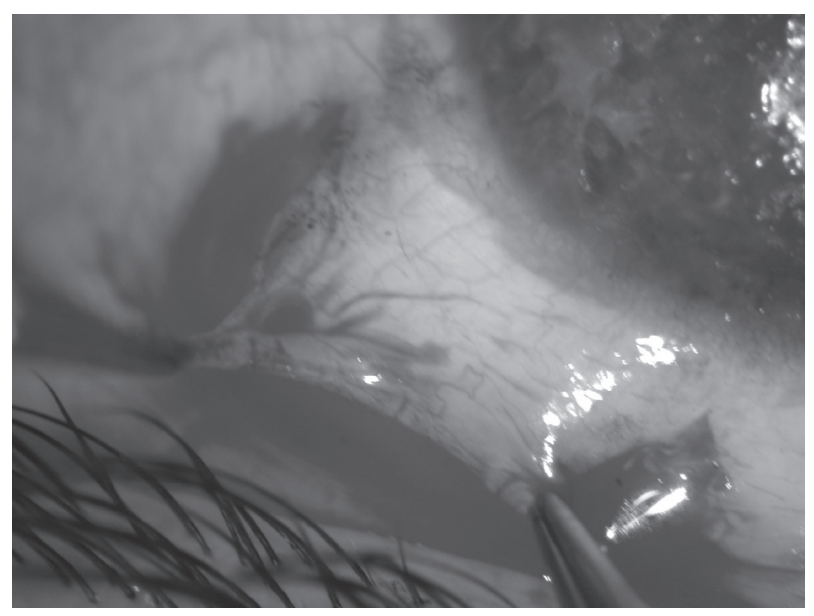

Figure 2 Removal of donor conjunctival graft. 


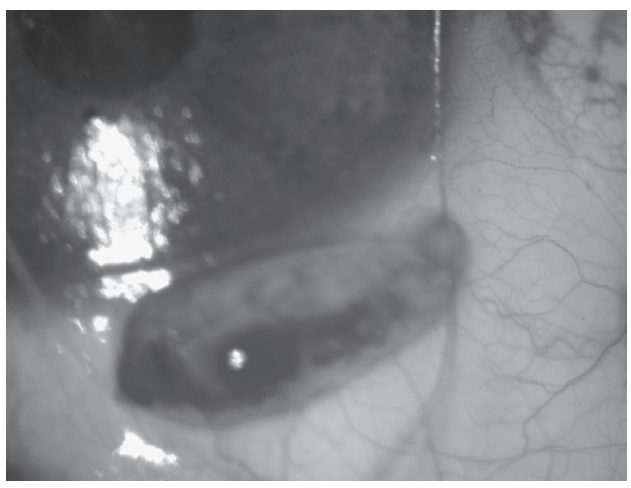

Figure 3 Transfer of graft to recipient area.

and was eliminated by topical steroid administeration, with an interval of 2 hours in 1 week. Three (16.6\%) patients developed recurrences within an average of 4 months. Three $(33.3 \%)$ of these cases were recurrent pterygia. No recurrence was seen in primary pterygia. Comparing the operation groups revealed that recurrence was highest in the bare sclera technique group and lowest in the conjunctival autografting group, with rates of $38.09 \%$ and $16.6 \%$, respectively. 63 primary and 14 recurrent pterygia underwent surgery. 15 (23\%) primary pterygia experienced recurrence whereas 7 (50\%) recurrent pterygia developed recurrence (Table 1). Recurrences were determined within 2-9 months after pterygia excision. Most recurrences were detected in 3-5 months. The mean recurrence periods of the various groups were: 4 months for bare sclera, 4 months for mitomycin C, 3 months for conjunctival flap technique, and 4 months for conjunctival autografting (Table 1). The ages of the patients included in the study were: 4 patients $20-29$ years, 13 patients $30-39$ years, 16 patients $40-49$ years, 21 patients 50-59 years, and 13 patients 60 years and older (Table 2). Recurrence was higher in the 40-49 years group. However no statistically significant difference was found between

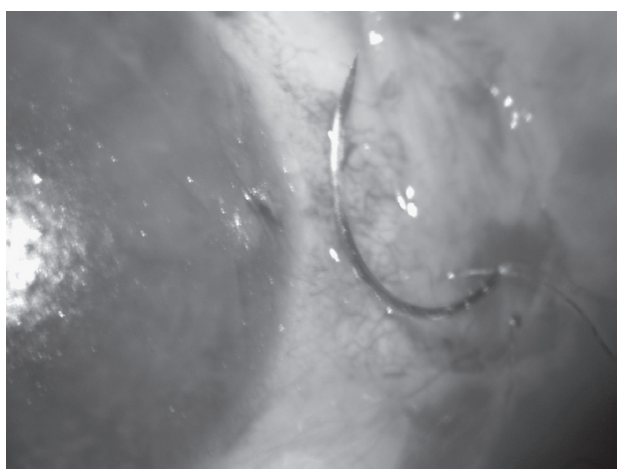

Figure 4 Suturing of graft to the excised pterygium side with 8/0 vicryl suture.

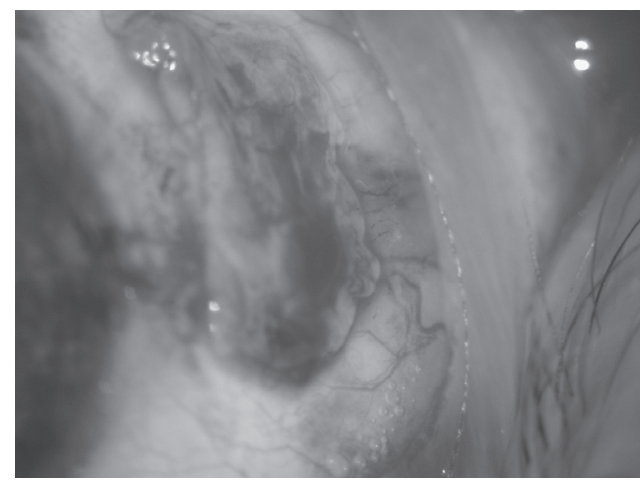

the groups $(\mathrm{P}=0.303)$. The most common postoperative complaint was irritation followed by photophobia, wetting, foreign body sensation, and hyperemia. Irritation was seen after the use of suturing techniques, for example in patients in the conjunctival flap and conjunctival autografting groups. To try and prevent these complaints, eyes were kept shut on the postoperative first day. In response to patient complaints, artificial tear drops were prescribed. No major complication threatening visual ability was encountered among the surgical patient groups.

\section{Discussion}

The recurrence of pterygium after surgical treatment remains a problem. Because of the difficulty of controlling this condition, various treatment modalities including radiotherapy, antimetabolite or antineoplastic drugs, conjunctival flap, and conjunctival or limbal autograft transplantation have been proposed. ${ }^{6}$ Generally, pterygium recurrences occur during the first 6 months after the surgery. ${ }^{7}$ A number of factors such as type of pterygium, age of patient, environment, and surgical technique may be responsible. ${ }^{6}$

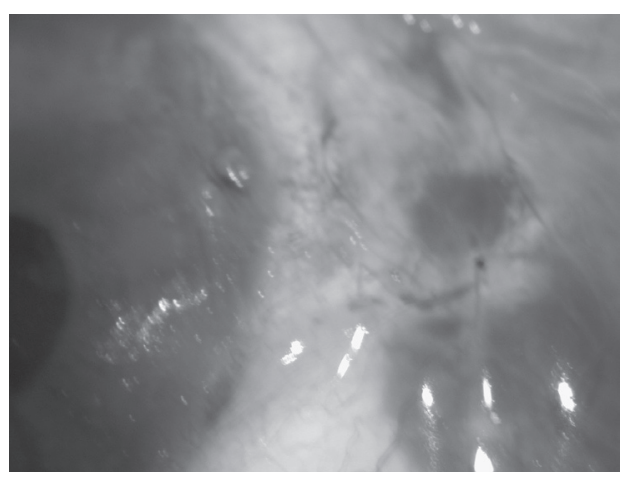


Table 2 Recurrence distribution with respect to age groups

\begin{tabular}{llll}
\hline Age distrubition & Eye & Recurrence & $\%$ \\
\hline $20-29$ & 4 & 0 & \\
$30-39$ & 13 & 3 & 23.07 \\
$40-49$ & 26 & 11 & 42.30 \\
$50-59$ & 21 & 5 & 23.80 \\
$60<$ & 13 & 3 & 23.07 \\
\hline
\end{tabular}

Demireller and colleagues reported 8 (42\%) recurrences in 19 eyes treated by bare sclera technique. ${ }^{8}$ Youngson declared the pterygium recurrence rate as $37 \%$ in 100 cases with the same technique, and concluded that this process is unhealthy and should not be used. ${ }^{9}$ Recurrence developed in $8(38.09 \%)$ of 21 cases in our series treated with excision and bare sclera technique. This technique is not recommended worldwide because it has no advantages other than being simple and time-saving.

Mitomycin C is an antibiotic isolated from Streptomyces caespitosis. It inhibits RNA, DNA, and protein synthesis and is usually used in systemic anticancer therapy. Kunitomo and Mori first described the topical use of mitomycin $\mathrm{C}$ to prevent pterygium recurrence in 1963 in Japan. ${ }^{7}$ Various concentrations of mitomycin $\mathrm{C}$ with different durations of application have been used, but the minimal safe and effective dosage and application time are still not certain. ${ }^{10}$ Rubinfeld and colleagues revealed reports of scleral ulceration, necrotizing scleritis, perforation, iridocyclitis, cataract, infection, glaucoma, scleral calcification, and loss of an eye after pterygium excision with adjunctive mitomycin $\mathrm{C}$ therapy. While the exact incidence of these complications is unknown, the safety of mitomycin $\mathrm{C}$ therapy remains to be determined with future long-term trials. ${ }^{11}$ After surgical excision, placing mitomycin $\mathrm{C}$ is a simple and time-saving method with a low recurrence rate. Nevertheless it has some dose-dependent complications, which can develop at any time. Patients should be followed up for a long time.

Rotational conjunctival flaps to cover the pterygium excisional site have been employed since the 1940s. ${ }^{3}$ The reported recurrence rates range from less than $1 \%$ to more than 5\%. Minimal to no complications apart from flap retraction and cyst formation have been reported. ${ }^{12}$ McCoombes and colleagues recently reported a recurrence rate of $3.2 \%$ by using a sliding conjunctival flap after primary pterygium excision in 258 eyes with an $86 \%$ follow-up rate for a minimum of 1 year. ${ }^{13}$ In our study, we followed up 18 pterygia patients treated with a flap technique within a period of 6-20 months; the recurrence rate was detected to be $33.33 \%$.
There were no serious complications in these cases. The most frequent symptom after this procedure was the formation of folds over the conjunctiva as a result of rotated tissues in the sliding flap area. Although these folds cause bad cosmesis, including hyperemia at the begining, after a time the conjunctiva improves and reaches an acceptable level cosmetically. Conjunctival flap tissue that is placed over bare sclera is adjacent to the excised pterygium tissue, and changed limbal cells that might be localised on the flap could contribute to the development of recurrence.

Conjunctival autograft transplantation was first described as a treatment for pterygium by Kenyon and colleagues in 1985. ${ }^{14}$ Starc and colleagues used this method on 57 eyes of 54 patients, nearly $80 \%$ of which were recurrent. The mean follow-up of 2 years detected only three (5.3\%) recurrences after autograft transplantation and found a $7.3 \%$ secondary recurrence in patients with recurrent pterygium. ${ }^{15}$ Güler and colleagues observed all of recurrent cases (13.3\%), which were followed up after autograft transplantation, in the under 40 year age group (16). These results suggest that the recurrence rate was highest in the $40-50$ year age group (42.30\%) in our series. There was no statistically significant difference between groups younger or older than 40 years. Starck and colleagues proposed that the efficient size of the autograft decreases the recurrence rate and this thesis is supported by Allan and colleagues. ${ }^{15,17}$ We have detected recurrence in $3(16.65 \%)$ of 18 cases treated with autografting in our series. All recurrent cases had previously undergone surgery. There was no recurrence after primary pterygia. In recurrent pterygium cases, the recurrence rate was found to be significantly high despite autografting. The cause was considered to be the incomplete excision of pathological tissues due to fibrosis. The first 4-6 month period following surgery, agreed on by all authors in case of recurrence, is shorter than the follow-up period of our study. Some authors prefer lower bulbus conjunctiva for autografting, considering that an autograft from superior bulbar conjunctiva might cause problems in probable filtration surgery. ${ }^{18}$ Syam and colleagues reported a recurrence rate of $3.3 \%$ in a study of 27 eyes. Recurrences were found to develop within 3 months after surgery. Conjunctival scar was reported to be $36.66 \%$ in the donor area. Hemorrhage under the autograft, corneal delen near the limbus, and epithelial inclusion cysts were reported in 3, 4, and 2 eyes, respectively. ${ }^{19}$ Koç and colleagues demonstrated that autografting from superior or inferior in primary cases caused no significant difference in recurrence, but in recurrent pterygia, autografting from inferior resulted in a higher recurrence tendency $(\mathrm{p}=0.166) .{ }^{20}$ In our study, 
graft tissue was gathered from the superior temporal region because of the possibility of a filtran surgery. Complications resulting from conjunctival autografting are rare and are no threat to vision. Allan and colleagues encountered one tenon granuloma, one conjunctival inclusion cyst, and three wound dehissence in a series of 93 cases, and concluded that the conjunctival autografting technique results in lower complication rates. ${ }^{17}$ All these complications were eliminated by minor surgical interventions. Vrabek and colleagues reported subconjunctival fibrosis at the autografting region in 2 cases, one of whom developed concommitant diplopia due to extraocular muscle restriction. ${ }^{21}$ Topical corticosteroids were suggested in order to prevent fibrosis. In most studies of autografting, retrobulber anesthesia was performed, which was reported to be one of the disadvantages of this technique. In our study, we have not determined any complications due to subconjunctival anesthesia;moreover, motions of the eye are no hindrance to the surgeon. In some patients, who are incapable of controlling eye motions, two traction sutures to the limbus at 12 and 6 o'clock were performed in order to prevent this problem. The disadvantages of the conjunctival autografting technique could be resolved as follows: a long operation time, the need for retrobulber anesthesia in some cases, limitation of the autograft diameter from the conjunctiva, and can cause problems in a probable fitration surgery. One of the other disadvantages of suturing is postoperative pricking. This effect might be minimized by placing the knot under the conjunctiva or using continuous suturing. In spite of all these difficulties, the recurrence rate is lower with this technique. After the operation, a smooth, white surface is achieved cosmetically. The disadvantage of the long operation time becomes an advantage with a low recurrence rate and no need for additional surgical intervention. As these are the most desired aims of surgery, the conjunctival autografting technique therefore deserves clear recognition.

In conclusion, according to this study we recommend that even in treating primary pterygium, additional methods should be used. When possible complications and morbidity are taken into account in the selection of this additional method, conjunctival autografting may be preferred.

\section{Disclosure}

The authors report no conflicts of interest in this work.

\section{References}

1. Taylor HR, West S, Munoz B, et al. The long-term effects of visible light on the eye. Arch Ophthalmol. 1992;110:99-104.

2. Tasman W, Jaeger EA. Duane's Clinical Ophthalmology. Philadelphia, PA: Lippincott Williams and Wilkins;2002;6:35.

3. Krachmer JH, Mannis MJ, Holland EJ, et al. Cornea. Philadelphia: Mosby;1998:1.

4. Al Fayez MF. Limbal versus conjunctival autograft transplantation for advanced and recurrent pterygium. Ophthalmology. 2002;109:1752-5.

5. Donnenfeld ED, Perry HD, Fromer S, et al. Subconjunctival mitomycin $\mathrm{C}$ as adjunctive therapy before pterygium excision. Ophthalmology. 2003;110:1012-16.

6. Mutlu FM, Sobaci G, Tatar T, et al. A Comparative Study of Recurrent Pterygium Surgery. Ophthalmology. 1999;106:817-21.

7. Adamis AP, Starck T, Kenyon KR. The management of pterygium. Ophthalmol Clin North Am. 1990;3:611-23.

8. Demireller T, Durak İ, Gürsel E, et al. [Primer ve rekürren pterjium tedavisinde Mitomycin C.] Oftalmoloji. 1992;4:329-31.

9. Youngson RM. Recurrence of pterygium after excision. Br JOphthalmol. 1972;56:120-5.

10. Lam DS, Wong AK, Fan DS, et al. Intraoperative Mitomycin C to prevent recurrence of pterygium after excision: a 30-month follow-up study. Ophthalmology. 1998;105:901-4.

11. Rubinfeld RS, Pfister RR, Stein RM, et al. Serious complications of topical mitomycin-C after pterygium surgery. Ophthalmology. 1992;99:1647-54.

12. Hirst LW. The treatment of pterygium. Surv Ophthalmol. 2003;48:145-80.

13. McCoombes JA, Hirst LW, Isbell GP. Sliding conjunctival flap for the treatment of primary pterygium. Ophthalmology. 1994;101:169-73.

14. Kenyon KR, Wagoner MD, Hettinger ME. Conjunctival autograft transplantation for advanced and recurrent pterygium. Ophthalmology. 1985;92:1461-70.

15. Starck T, Kenyon KR, Serrano F. Conjunctival autograft for primary and recurrent pterygia: surgical technique and problem management. Cornea. 1991;10:196-202.

16. Güler M, Sobacı G, İlker S. Limbal-conjunctival autograft transplantation in cases with recurrent pterygium. Acta Ophthalmol. 1994;72:721-6.

17. Allan BD, Short P, Crawford GJ, et al. Pterygium excision with conjunctival autografting: an effective and safe technique. Br JOphthalmol. 1993;77:698-701.

18. Broadway DC, Grierson I, Hitchings RA. Local effects of previous conjunctival incisional surgery and the subsequent outcome of filtration surgery. Am J Ophthalmol. 1998;125:805-18.

19. Syam PP, Eleftheriadis H, Liu CSC. Inferior conjunctival autograft for primary pterygia. Ophthalmology. 2003;110:806-10.

20. Koç F, Demirbay P, Teke MY, et al. [Primer ve rekürren pterjiumda konjonktival otogreftleme.] T Oft Gaz. 2002;32:583-8.

21. Vrabec MP, Weisenthal RW, Elsing SH. Subconjunctival fibrosis after conjunctival autograft. Cornea. 1993;12:181-3. 